\title{
Younger and older adults' collaborative recall of shared and unshared emotional pictures
}

\author{
Sarah J. Barber ${ }^{1,2}$ • Jaime J. Castrellon ${ }^{1} \cdot$ Philipp Opitz $^{1} \cdot{\text { Mara } \text { Mather }^{1}}^{1}$
}

Published online: 21 February 2017

(C) Psychonomic Society, Inc. 2017

\begin{abstract}
Although a group of people working together recalls more items than any one individual, they recall fewer unique items than the same number of people working apart whose responses are combined. This is known as collaborative inhibition, and it is a robust effect that occurs for both younger and older adults. However, almost all previous studies documenting collaborative inhibition have used stimuli that were neutral in emotional valence, low in arousal, and studied by all group members. In the current experiments, we tested the impact of picture-stimuli valence, picture-stimuli arousal, and information distribution in modulating the magnitude of collaborative inhibition. We included both younger and older adults because there are age differences in how people remember emotional pictures that could modulate any effects of emotion on collaborative inhibition. Results revealed that when information was shared (i.e., studied by all group members), there were robust collaborative inhibition effects for both neutral and emotional stimuli for both younger and older adults. However, when information was unshared (i.e., studied by only a single group member), these effects were attenuated. Together, these results provide mixed support for the retrieval strategy disruption account of collaborative inhibition. Supporting the retrieval strategy disruption account, unshared study information was less susceptible to collaborative inhibition than shared study information. Contradicting the retrieval strategy disruption account, emotional valence and arousal did not modulate the magnitude of collaborative inhibition despite the fact that participants
\end{abstract}

Sarah J. Barber

barber@sfsu.edu

1 University of Southern California, Los Angeles, CA, USA

2 Department of Psychology, San Francisco State University, San Francisco, CA 94132, USA clustered the emotional, but not neutral, information together in memory.

Keywords Group memory · Aging · Emotion · Collaborative inhibition

Collaborative recall is not always beneficial. Although a group of people working together recalls more than any one individual (e.g., Perlmutter \& De Montmollin, 1952), they recall fewer unique items than the same number of people working apart whose responses are nonredundantly aggregated. In other words, when it comes to the quantity of information that people can recall, the whole (i.e., the collaborative group) is less than the sum of its parts (i.e., the nominal group). This is known as collaborative inhibition (Weldon \& Bellinger, 1997; for reviews, see Rajaram, 2011; Rajaram \& Pereira-Pasarin, 2010).

Although collaborative inhibition clearly occurs in free recall for a wide variety of study stimuli (see Marion \& Thorley, 2016), almost all prior research has used stimuli that were neutral in emotional valence and low in emotional arousal. However, in the few studies that have used emotionally evocative stimuli, collaborative inhibition has typically still occurred. Yaron-Antar and Nachson (2010) found collaborative inhibition when groups of Israeli students were tested on their memory of the details concerning the assassination of Israeli Prime Minister Itzhak Rabin. Similarly, collaborative inhibition has been observed in female undergraduates' memory for a film clip depicting a fatal car accident (Bärthel, Wessel, Huntjens, \& Verwoerd, in press; Wessel, Zandstra, Hengeveld, \& Moulds, 2015). In contrast to these findings, a recent study found no evidence of collaborative inhibition when examining couples' memory for the emotional scene of a play depicting rape and murder (Vredeveldt, 
Hildebrandt, \& von Koppen, 2016). However, this may have been due to the fact that the group members knew each other well and likely had an established transactive memory system (Wegner, 1987; Wegner, Giuliano, \& Hertel, 1985). Prior research has shown that under such circumstances collaborative inhibition is often reduced or eliminated for neutral stimuli (e.g., Andersson \& Rönnberg, 1995, 1996; Johansson, Andersson, \& Rönnberg, 2005; see also Marion \& Thorley, 2016).

Although all prior studies have found collaborative inhibition when unacquainted individuals attempt to recall negatively valenced stimuli, only one prior study has concurrently included neutral or positively valenced stimuli. However, the effects of valence on collaborative inhibition were not reported (Harris, Barnier, \& Sutton, 2012). Furthermore, no previous study has also included negative stimuli that varied in arousal levels. Thus, it is not clear whether the magnitude of collaborative inhibition varies as a function of the stimuli's emotional valence or emotional arousal. The primary aim of this study was to address this issue.

\section{Collaborative inhibition of emotional stimuli: Predictions from the retrieval strategy disruption account}

Collaborative inhibition is most often explained as arising due to retrieval strategy disruption. According to this theory, individuals develop their own unique organization of the study materials and use these idiosyncratic organizational schemes to guide their retrieval. However, being exposed to a subset of the items (provided by group members during collaborative recall) disrupts people from being able to effectively use their organizational strategies and reduces the quantity of information that they recall (Basden, Basden, Bryner, \& Thomas, 1997). Importantly, not all information is equally susceptible to retrieval strategy disruption. Although collaborative inhibition should only occur when participants have some minimal organizational scheme to disrupt (Pereira-Pasarin \& Rajaram, 2011), it is also the case that stronger organizational schemes should be less susceptible to retrieval strategy disruption than weak organizational schemes (e.g., Blumen \& Rajaram, 2008; Blumen \& Stern, 2011; Congleton \& Rajaram, 2011; PereiraPasarin \& Rajaram, 2011).

This leads to the hypothesis that collaborative inhibition may be affected by the emotionality of the stimuli. Although people impose idiosyncratic organizational schemes on lists of seemingly unrelated, neutral stimuli (Shuell, 1969; Tulving, 1965; Wallace, 1970), organizational strength is stronger for emotional stimuli than for neutral stimuli. This is because negative and positive information can be thought of as constituting semantic categories. This semantic cohesion can lead to greater relational processing at encoding and the creation of stronger interitem associations for emotional, relative to neutral, stimuli (e.g., Buchanan, Etzel, Adolphs, \& Tranel, 2006; Talmi \& Moscovitch, 2004; Talmi, Schmmack, Paterson, \& Moscovitch, 2007; Tulving \& Pearlston, 1966). For example, after studying negative, neutral, and positive words, people engage in "emotional clustering"; they are more likely to recall the emotional, compared to the neutral, words together (Long, Danoff, \& Kahana, 2015; Siddiqui \& Unsworth, 2011). This strong organizational clustering should in turn make emotional stimuli less susceptible to retrieval strategy disruption than neutral stimuli, and therefore less susceptible to collaborative inhibition. This may be particularly true for negative, high-arousal stimuli, since emotional clustering is greatest for these items (Long et al., 2015).

However, it is alternately possible that the magnitude of collaborative inhibition is invariant to emotional valence. Although some research has found that participants use emotional valence as a category cue (e.g., by clustering emotional items together in recall; Siddiqui \& Unsworth, 2011), others have failed to observe this effect (Manning \& Julian, 1975; Zimmerman \& Kelley, 2010), or have found that such effects are more likely to occur when participants are specifically oriented to focus on the emotionality of the items (Siddiqui \& Unsworth, 2011). This undermines the argument that people automatically use emotion as a category cue and that the organizational schemes of emotional stimuli are stronger than those of neutral stimuli. If emotional valence does not affect organizational strategies, then there is no reason to predict that it will affect retrieval strategy disruption and collaborative inhibition. To further shed light on these issues, in this study we examined whether participants spontaneously engage in emotional clustering, and if so, whether emotional clustering can reduce collaborative inhibition.

\section{Collaborative inhibition of emotional stimuli as a function of age}

The primary aim of this study was to determine whether the magnitude of collaborative inhibition varies between emotionally evocative and neutral stimuli. However, in doing so, we considered participant age as a potential moderating factor. Although previous research has shown that collaborative inhibition occurs for older adults (e.g., Johansson et al., 2005; Ross, Spencer, Linardatos, Lam, \& Perunovic, 2004), and that the magnitude of collaborative inhibition is age-invariant between younger and older adults (e.g., Blumen \& Stern, 2011; Henkel \& Rajaram, 2011; Meade \& Roediger, 2009; Ross, Spencer, Blatz, \& Restorick, 2008), all previous studies with older adults have used neutral stimuli. In this study, we examined whether collaborative inhibition is also age invariant 
when using emotionally evocative stimuli. One reason for examining this is because there are age differences in the type of emotional stimuli that younger and older adults attend to and remember. Compared with younger adults, older adults show a relative preference to attend to and remember positive over negative stimuli (Charles, Mather, \& Carstensen, 2003; Mather \& Carstensen, 2005; Mather \& Knight, 2005). This age-by-valence interaction is known as the positivity effect (Kennedy, Mather, \& Carstensen, 2004; for a recent meta-analysis, see Reed, Chan, \& Mikels, 2014).

Although positivity effects are usually conceptualized as age differences in attention and memory for objectively positive and negative stimuli, they can also be conceptualized as older adults looking for the good in bad (or ambiguous) situations. In general, older adults' emotional experiences are more complex, with mixed emotions occurring more frequently (Carstensen, Pasupathi, Mayr, Nesselroade, 2000; Labouvie-Vief \& Medler, 2002). Older adults are also more likely to interpret negative stimuli as having positive qualities. For example, they are more likely to interpret negative and ambiguous facial expressions as representing a mix of positive and negative emotions (Kellough \& Knight, 2012). They also appraise unpleasant social situations more positively (Luong \& Charles, 2014), and expect ambiguous situations to have more positive outcomes (Mikels \& Shuster, 2016).

These age differences in emotional processing may in turn modulate the magnitude of collaborative inhibition for emotional stimuli. Because older adults interpret negative stimuli as representing a mix of negative and positive emotions (e.g., Kellough \& Knight, 2012), they may categorize "negative" and "positive" stimuli in a less differentiated manner. Because of this, valence may be less effective as a category cue for older adults, and they may be less likely to cluster the stimuli based upon its valence. This in turn should reduce the benefits of reduced retrieval strategy disruption and collaborative inhibition that this is predicted to bring.

\section{Collaborative inhibition as a function of information distribution}

Finally, in this study we also considered the role of information distribution. When people collaboratively reminisce about the past, there is some information that all group members have access to (i.e., shared information). However, there is also some information that is uniquely known by each individual (i.e., unshared information). Although both unshared and shared stimuli can disrupt retrieval schemes by causing a category switch or by cross-cuing other memories within a category, only shared stimuli can disrupt preferred output order (since, by definition, a group member's unshared information could not have been included in a participant's individual retrieval plan). Because of this, according to the retrieval strategy disruption account, collaborative inhibition should be attenuated for unshared information. However, to our knowledge, only two prior studies have directly contrasted the magnitude of collaborative for shared and unshared stimuli, and neither have supported this hypothesis. In fact, in the first study to investigate this issue, Meade and Gigone (2011) found that collaborative inhibition was greater for unshared than for shared stimuli (Experiment 1). Although this effect was only marginally significant, it was explained as arising from social interaction factors. In this first study, the unshared stimuli was less likely to be acknowledged by the group members and less likely to be written down on the recall response sheet (see also Ekeocha \& Brennan, 2008, for evidence of group filtering). This is similar to other research suggesting that collaborative groups adopt a more stringent recall criteria that minimizes errors (e.g., Ross et al., 2008), and may have a greater focus on developing a version of the event that is agreed upon by all group members (see Hyman, Cardwell, \& Roy, 2013). In support of this, in a second experiment, Meade and Gigone (2011) found that collaborative inhibition occurred at equivalent levels for unshared and shared stimuli once category cues were provided. The authors hypothesized that this was because the category cues served as an experimenter-provided confirmation that the unshared stimuli could have been part of the studied set. However, in another study, Gummerum, Leman, and Hollins (2013) found no significant difference in collaborative inhibition of unshared and shared stimuli despite the fact that no category labels were provided.

Thus, previous research examining the role of information distribution on collaborative inhibition has been inconclusive, with one experiment reporting marginally greater collaborative inhibition for unshared stimuli and two reporting no significant differences. In this study we further tested this issue, and also examined the potential role of emotional valence and arousal in modulating this effect. Emotional stimuli are often recalled at higher rates (see Bradley, Greenwald, Petry, \& Lang, 1992; Choi, Kensinger, \& Rajaram, 2013; Kensinger, 2007; Mather, 2007; Mather \& Sutherland, 2011) and with greater feelings of recollection (see Ochsner, 2000; Poldrack, Wagner, Phelps \& Sharot, 2008; Sharot, Delgado, \& Phelps, 2004). Because of this, we hypothesized that people may be willing to include unshared emotional stimuli in the group memory report regardless of group interaction factors. Furthermore, the emotional category itself (e.g., "positive stimuli") may act as a category cue and eliminate differences in the magnitude of collaborative inhibition between the shared and unshared information. 


\section{The current study}

We examined whether collaboration differentially affects the recall of emotional versus neutral stimuli and whether effects depend upon participant age and information distribution. To do this, we recruited groups of younger and older adult participants and exposed them to pictures that were positive, neutral, or negative in valence. Positive and negative pictures were equally often low and high in arousal. Whereas most pictures were studied by both group members, a subset was uniquely studied by each individual. Participants then attempted to recall those items either alone (and their responses were combined with those of another participant to create a nominal group recall) or with a partner (in a collaborative group). All participants then completed a subsequent, always-individual, recall test.

Although our primary outcome of interest was collaborative inhibition, we also included a final, always-individual, recall test, because collaboration often leads to higher accuracy on subsequent individual memory tests (e.g., Blumen \& Rajaram, 2008, 2009; Blumen \& Stern, 2011; Blumen, Young, \& Rajaram, 2014; Choi, Blumen, Congleton, \& Rajaram, 2014; Henkel \& Rajaram, 2011; Rajaram \& Pereira-Pasarin, 2007; Weldon \& Bellinger, 1997; Wissman \& Rawson, 2015). This benefit is thought to occur because collaborative recall can serve as a second study opportunity, reexposing participants to items that they had forgotten but that their group members recalled. It can also occur as a function of cross-cuing, wherein hearing a group member's recall cues the individual to recall additional information (see Harris, Keil, Sutton, Barnier, \& Mcllwain, 2011). Thus, factors that reduce collaborative inhibition should also lead to greater benefits on subsequent individual memory tests (see Congleton \& Rajaram, 2011).

\section{Method}

\section{Design}

The experiment involved a 2 (retrieval condition: collaborative or nominal recall) $\times 2$ (age group: older adults or younger adults) $\times 5$ (picture stimulus type: positive high arousal, positive low arousal, neutral, negative low arousal, or negative high arousal) $\times 2$ (information distribution: shared or unshared items) design. Retrieval condition and group composition were manipulated between-subjects while the picture stimulus type and information distribution were manipulated within subjects.

\section{Participants}

Data were collected in two waves. Wave 1 consisted of 60 younger adults and 58 older adults. ${ }^{1}$ Wave 2 consisted of 74 younger adults and 57 older adults. Data from six younger adults in Wave 2 were excluded because of experimenter error (i.e., each dyad member saw the same set of pictures, and there were no unshared items to analyze). Because there was not an even number of older adult participants tested during Wave 2, data from one older adult were also excluded. This left a final sample size of 242 individuals (128 younger adults and 114 older adults). The younger adults were undergraduate students (33 men, 95 women) who ranged in age from 18 to 31 years $(M=19.86, S D=1.78)$. The older adults were communitydwelling individuals (50 men, 64 women) who ranged in age from 62 to 87 years old $(M=71.89, S D=5.83)$. For more demographic information, please see Table 1 . None of the reported patterns of data change when including data collection wave ( 1 or 2$)$ as a covariate in the analyses.

We varied whether participants were tested individually or with a collaborative partner of the same age. Of the 128 younger adults, 62 were tested individually (and later formed 31 all-younger-adult nominal dyads) and 66 were tested in a group setting with another younger adult participant (and formed 33 all-younger-adult collaborative dyads). Of the 114 older adults, 56 were tested individually (to later form 28 allolder-adult nominal dyads), and 58 were tested in a group setting with another older adult participant (and formed 29 all-older-adult collaborative dyads). According to G*Power 3.1 (Faul, Erdfelder, Lang, \& Buchner, 2007), this sample size provided $80 \%$ power to detect an interaction of at least $f=0.10$ between retrieval condition and picture stimulus type (assuming a correlation of 0.5 between the repeated measures). According to Cohen's (1988) effect-size conventions, 0.40, 0.25 , and 0.10 indicate large, medium, and small effect sizes, respectively. Thus, we had the power to detect even a small effect of picture stimulus type in modulating the magnitude of collaborative inhibition.

Participants in both waves of data collection were recruited through the University of Southern California (USC) psychology participant pool and through a list of research volunteers recruited via newspaper and online ads, fliers at senior centers

\footnotetext{
${ }^{1}$ During Wave 1 , we recruited an additional 27 younger adults and 27 older adults who completed the experiment in mixed-age dyads ( 13 nominal and 14 collaborative dyads). Although these data are not discussed further, it is worth noting that a numeric pattern consistent with collaborative inhibition also occurred for these participants. Although collaborative inhibition was not statistically significant when examining only the mixed-age dyads, $F(1,25)=$ $2.55, p=.12, \eta_{\mathrm{p}}{ }^{2}=.09$, within Wave 1 the magnitude of collaborative inhibition did not significantly vary as a function of age group composition. In a 2 (retrieval condition: collaborative or nominal recall) $\times 3$ (age group composition: older adults vs. younger adults vs. mixed ages) ANOVA on the total number of pictures recalled, there was no significant interaction between retrieval condition and age group composition, $F(1,80)=0.15, p=.86, \eta_{\mathrm{p}}{ }^{2}=$ .004 .
} 
Table 1 Participant characteristics as a function of age (standard deviations are presented in parentheses)

\begin{tabular}{lll}
\hline & Younger adults $(n=128)$ & Older adults $(n=114)$ \\
\hline Age* & $19.86(1.78)$ & $71.89(5.83)$ \\
Gender & $74 \%$ female & $55 \%$ female \\
Education (years) & $13.68(1.30)$ & $16.26(2.79)$ \\
Self-reported health $(1=$ very poor health ... 9 = excellent health) & $7.44(1.22)$ & $7.09(1.87)$ \\
Self-reported stress* $(1=$ very low... 9 = very high) & $4.80(1.91)$ & $2.80(2.04)$ \\
Self-reported stress compared to normal $(1=$ much lower... 5 = same as usual... 9= much higher $)$ & $4.76(1.90)$ & $4.73(1.59)$ \\
ERQ Reappraise & $30.52(5.32)$ & $29.48(7.82)$ \\
ERQ Suppress* & $15.57(7.07)$ & $12.50(4.59)$ \\
Anxiety: Recall Test 1 & $3.95(2.59)$ & $4.25(2.93)$ \\
Anxiety: Recall Test 2 & $3.92(2.72)$ & $4.05(2.96)$ \\
Anxiety: Recall Test 3 & $4.13(2.87)$ & $4.05(2.95)$ \\
Perceptions of age-related stereotype threat* & $10.08(2.83)$ & $13.34(3.29)$
\end{tabular}

Note: Independent samples $t$ tests were used to compare the younger and older adults on each of the numeric demographic variables. Asterisks indicate variables on which there were significant age differences $(p<.05)$

and public places, and letters to USC alumni. Upon completion of the study, participants were compensated either one credit/hour toward their course requirements or $\$ 15 /$ hour.

\section{Materials}

Stimuli consisted of 80 pictures previously used by Mather and Knight (2005, Experiment 2), which were selected to be distinguishable from one another based on verbal descriptions. Of these, 16 were neutral, 32 were positive, and 32 were negative in valence. The majority of these pictures came from the International Affective Pictures System (IAPS; Lang, Bradley, \& Cuthbert, 1999). However, two neutral pictures came from additional sources. Within the negative and positive valence categories, an equal number of pictures (16) were low and high in emotional arousal. Previous results from Mather and Knight (2005, Experiment 2) showed that younger and older adults did not differ in their valence or arousal ratings of these pictures.

We manipulated the information distribution of the stimuli. Within each dyad (either nominal or collaborative), 60 of the 80 pictures were "shared" and studied by both group members. The remaining 20 pictures were "unshared"; 10 were studied only by one participant and the other 10 were studied only by that participant's collaborative partner. For each participant, the 10 unshared studied items were distributed as follows: two were neutral, two were negative in valence and low in arousal, two were negative in valence and high in arousal, two were positive in valence and low in arousal, and two were positive in valence and high in arousal. Thus, although there were 80 pictures studied by each dyad, a given participant was only exposed to 70 pictures. Counterbalancing was used such that across participants each picture was equally likely to appear as an unshared item across dyads.

\section{Procedure}

Encoding Each participant sat at his or her own computer and saw 70 pictures (that varied in stimulus type) at a rate of one picture every 5 seconds, with an interstimulus interval of $750 \mathrm{~ms}$. Participants were told to study the pictures in preparation for an upcoming memory test. No mention was made about whether the memory test would be conducted individually or collaboratively or that participants in the dyad would be studying slightly different sets of pictures.

Filled delay During a 15-minute retention interval, participants first completed a vocabulary assessment on the computer. However, because of experimenter error, these were improperly saved and will not be discussed further. Participants also completed a demographics questionnaire as well as the Emotion Regulation Questionnaire, which assesses whether participants tend to regulate their emotions using cognitive reappraisal or expressive suppression (ERQ; Gross \& John, 2003). For descriptive analyses of these questionnaires, see Table 1. Remaining time (if any) was spent individually completing puzzles.

Recall Test 1: Initial individual memory test After the delay period, participants completed an individual free recall test. Here, participants were placed in separate rooms and asked to spend 10 minutes recalling as many of the pictures as they could. Participants were asked to describe the pictures aloud, and an experimenter typed their responses into a computer whose screen was clearly visible 
to the participant. When responses provided were too vague to be clearly matched to a single picture (e.g., violence), the experimenter prompted the participant to provide additional details.

\section{Recall Test 2: Group (nominal or collaborative) memory} test Immediately after Recall 1, participants completed a second free recall test for 10 minutes. In the nominal groups, this test was identical to the one they had just completed. In the collaborative groups, the participants were moved to be in the same room and worked in dyads. No specific instructions were provided about how to collaborate or how to resolve disputes. During Wave 1, collaborative groups were videotaped; this was a back-up measure to ensure that all items recalled during the collaborative conversations were recorded by the experimenter. To remove this procedural difference between the collaborative and nominal groups, during Wave 2 all participants were videotaped. As before, the participants completed the recall test aloud, and an experimenter typed their responses into a computer whose screen was clearly visible to participants. The experimenter prompted for additional details on vague responses.
Recall Test 3: Final individual memory test Immediately after Recall 2, all participants completed a third free recall test for 10 minutes. Regardless of condition, participants here worked individually. In the case of collaborative groups, one group member was moved so that the two participants were again in separate rooms. They recalled items aloud, and an experimenter typed their responses into a computer whose screen was clearly visible to the participant. The experimenter prompted for additional details on vague responses.

Final questionnaires Participants next completed a series of questionnaires. We assessed perceptions of age-related stereotype threat (Chasteen, Bhattacharyya, Horhota, Tam, \& Hasher, 2005) and self-reported anxiety during each of the memory tests (Osborne, 2001). For more details, see Table 1. Participants also completed the Perceptions About Collaboration Questionnaire (Henkel \& Rajaram, 2011), which assesses how often participants engage in collaboration in their everyday lives, how effective they view collaborative recall to be, and what factors influence the efficacy of collaborative recall (e.g., age of collaborative partner and group size; for more details, see Table 2).

Table 2 Average ratings on the perceptions of collaboration questionnaire as a function of age group and retrieval condition

\begin{tabular}{|c|c|c|c|c|c|}
\hline & \multicolumn{2}{|c|}{ Younger adults } & \multicolumn{2}{|c|}{ Older adults } & \multirow[t]{2}{*}{ Significant main effects } \\
\hline & Nominal & Collaborative & Nominal & Collaborative & \\
\hline $\begin{array}{l}\text { How helpful to remember alone/with other participant on picture list } \\
\text { memory task }(1=\text { very harmful } \ldots 5=\text { very helpful }) . \text { Note: } \\
\text { question wording varied between nominal and collaborative } \\
\text { individuals }\end{array}$ & 2.75 & 4.33 & 3.02 & 4.40 & Nominal $<$ Collaborative \\
\hline $\begin{array}{l}\text { How helpful to remember in group on everyday memory tasks } \\
\qquad(1=\text { very harmful... } 5=\text { very helpful })\end{array}$ & 4.13 & 4.33 & 4.15 & 4.42 & Nominal $<$ Collaborative \\
\hline $\begin{array}{l}\text { Age of most successful collaborators on picture list memory task } \\
(1=20 \mathrm{~s}, 2=30 \mathrm{~s}, 3=40 \mathrm{~s}, 4=50 \mathrm{~s}, 5=60 \mathrm{~s}, 6=70 \mathrm{~s}, 7=80 \mathrm{~s})\end{array}$ & 1.28 & 1.11 & 2.85 & 3.00 & Young $<$ Old \\
\hline $\begin{array}{l}\text { Age of most successful collaborators on everyday memory tasks } \\
\qquad(1=20 \mathrm{~s}, 2=30 \mathrm{~s}, 3=40 \mathrm{~s}, 4=50 \mathrm{~s}, 5=60 \mathrm{~s}, 6=70 \mathrm{~s}, 7=80 \mathrm{~s})\end{array}$ & 1.40 & 1.19 & 2.92 & 3.07 & Young $<$ Old \\
\hline $\begin{array}{l}\text { Ideal \# of collaborators for success on picture list memory task } \\
(1=\text { alone, } 2=\text { one person, } 3=\text { two people, } 4=\text { three people } \\
5=\text { four or more people })\end{array}$ & 1.39 & 1.67 & 1.40 & 1.53 & \\
\hline $\begin{array}{l}\text { Ideal \# of collaborators for success on everyday memory tasks } \\
\quad(1=\text { alone }, 2=\text { one person, } 3=\text { two people, } 4=\text { three people, } \\
5=\text { four or more people })\end{array}$ & 1.39 & 1.50 & 1.25 & 1.29 & \\
\hline $\begin{array}{l}\text { Preference to remember alone without relying on others to remind } \\
\text { me }(1=\text { strongly disagree... } 5=\text { strongly agree })\end{array}$ & 3.60 & 3.70 & 3.83 & 3.64 & \\
\hline $\begin{array}{l}\text { Frequency ask for reminders to do future task }(1=\text { never } \ldots \\
\quad 5=\text { very often })\end{array}$ & 2.58 & 2.64 & 2.60 & 2.64 & \\
\hline $\begin{array}{l}\text { Frequency rely on others to remember information }(1=\text { never } \ldots \\
5=\text { very often })\end{array}$ & 2.42 & 2.47 & 2.46 & 2.60 & \\
\hline $\begin{array}{l}\text { Change in frequency of relying on others to remember things in } \\
\text { past } 10 \text { years }(1=\text { much more often } \ldots 5=\text { much less often })\end{array}$ & 3.36 & 3.19 & 2.69 & 2.51 & Young $>$ Old \\
\hline
\end{tabular}

Note: Separate 2 (age group) $\times 2$ (retrieval condition) ANOVAs were used to determine the influence of age and retrieval condition on each of these ratings. Main effects $(p<.05)$ are reported in the far right column. There were no significant interactions between age group and retrieval condition 


\section{Results}

\section{Recall coding}

On each recall test, a picture was scored as correctly recalled if the description provided by the participant clearly matched one of the studied pictures. Recalled pictures were then classified to picture stimulus type (positive high arousal, positive low arousal, neutral, negative low arousal, or negative high arousal) based upon their normative IAPS ratings. Most unscored responses were descriptions that were too general to be matched to a picture (e.g., something on a table; children). However, there were also some descriptions that did not match studied pictures (e.g., drive-in movie theater with an empty lot; horizon shot of Paris and the Eiffel tower).

Wave 1 recall was coded by the first author (S.B.), and Wave 2 recall was coded by a research assistant (L.E.). To ensure that the ratings were reliable, the second author (J.C.) independently coded approximately $20 \%$ of the Wave 1 recall protocols, and the first author (S.B.) independently coded approximately $20 \%$ of the Wave 2 recall protocols. These were randomly selected, with the constraint that they evenly came from younger and older adult participants and from nominal and collaborative groups. Reliability with the primary raters was extremely high in both Wave 1 (97.9\% agreement, Cohen's kappa $=.95, p<.001)$, and Wave $2(97.6 \%$ agreement, Cohen's kappa $=.95, p<.001$ ).

\section{Individual recall performance before collaboration (Recall Test 1)}

Recall Test 1 served as a baseline memory test and was always completed individually. This test allowed us to determine whether participants use emotion as a category cue and clustered the emotional pictures together in their recall output. It also allowed us to ensure that participants assigned to the nominal and collaborative groups during Recall Test $2 \mathrm{did}$ not vary in their baseline memory abilities.

To assess for emotional clustering, transition probabilities were calculated following the procedure outlined by Siddiqui and Unsworth (2011). These transition probabilities represent the probability of recalling a certain type of picture given the identity of the item that had most recently been recalled (e.g., the probability of recalling a negative high arousal picture given that that the most recent previously recalled picture was a negative high arousal picture vs. a neutral picture). Given that there were five picture stimulus categories (positive high arousal, positive low arousal, neutral, negative low arousal, or negative high arousal), a transition probability of 0.20 represents chance (for additional details, please see Appendix A).

Because transition probabilities are calculated separately for each of the five stimulus picture types, and therefore use different denominators, it is not possible to directly compare them. Thus, to assess for emotional clustering, we instead tested whether transition probabilities within each of the five picture stimulus categories exceeded chance (.20). Results indicated that emotional clustering did occur. A series of one-sample $t$ tests showed that within-category transition probabilities exceeded chance for the negative high arousal pictures $(M=.39), t(239)=16.44, p<.001, d=2.13$, positive high arousal pictures $(M=.28), t(221)=4.90, p<.001, d=$ .66 , and positive low arousal pictures $(M=.28), t(230)=6.36$, $p<.001, d=.84$. In contrast, participants did not significantly cluster together either the negative low arousal $(M=.22)$, $t(206)=1.41, p=.16, d=.20$, or neutral pictures $(M=.19)$, $t(189)=-0.43, p=.67, d=.06$. This pattern did not depend upon participant age; identical results were obtained when examining the younger and older adults separately.

We next examined baseline memory accuracy. Although this baseline test was always conducted individually, to ease comparison of the results across memory tests, we computed group recall accuracy. This was done by pooling the nonredundant items recalled by each dyad member, both for participants who would be future members of nominal groups during Recall Test 2 as well as for participants who would be future members of collaborative groups during Recall Test 2 .

We then evaluated baseline memory accuracy using a 2 (retrieval condition: collaborative or nominal recall) $\times 2$ (age group: older adults or younger adults) $\times 5$ (picture stimulus type: positive high arousal, positive low arousal, neutral, negative low arousal, or negative high arousal) $\times 2$ (information distribution: shared or unshared items) ANOVA on the proportion of pictures correctly recalled by each group during Recall Test 1 . Within this analysis there was no significant main effect of retrieval condition, $F(1,117)=0.31, M S E=$ $.10, p=.58, \eta_{\mathrm{p}}{ }^{2}=.003$, and no significant interactions involving retrieval condition (all $p s>.21$ and $\eta_{\mathrm{p}}{ }^{2}<.014$ ). Thus, the participants assigned to the nominal and collaborative groups for Recall Test 2 did not vary in their baseline memory abilities during Recall Test 1.

We next examined how baseline memory accuracy was affected by age group, picture stimulus type, or information distribution. Within the aforementioned 2 (retrieval condition) $\times 2$ (age group) $\times 5$ (picture stimulus type $) \times 2$ (information distribution) ANOVA, there were only four significant effects. There was a main effect of information distribution, $F(1,117)=250.83, M S E=.04, p<.001, \eta_{\mathrm{p}}{ }^{2}$ $=.68$, which interacted with picture stimulus type, $F(4$, $468)=23.86, M S E=.05, p<.001, \eta_{\mathrm{p}}{ }^{2}=.17$. Consistent with prior research (e.g., Meade \& Gigone, 2011; Stasser, Vaughan, \& Stewart, 2000; Stewart, Stewart, Tyson, Vinci, \& Fioti, 2004), participants were more likely to recall shared pictures $(M=.49)$ compared with unshared pictures $(M=.32)$. However, this tendency was particularly pronounced for the high arousal negative pictures and was absent for the neutral pictures (see Table 3). 
Table 3 Proportion of the 60 shared and 20 unshared pictures remembered by each group during Recall Test 1 as a function of picture stimulus type and age group (collapsing across future nominal and collaborative groups). Numbers in parentheses represent the standard deviations

\begin{tabular}{|c|c|c|c|c|c|}
\hline & Positive high arousal & Positive low arousal & Neutral & Negative low arousal & Negative high arousal \\
\hline \multicolumn{6}{|c|}{ Younger adults } \\
\hline Shared & $.46(.19)$ & $.54(.16)$ & $.36(.18)$ & $.44(.16)$ & $.72(.17)$ \\
\hline Unshared & $.30(.25)$ & $.32(.25)$ & $.41(.27)$ & $.25(.22)$ & $.39(.26)$ \\
\hline \multicolumn{6}{|c|}{ Older adults } \\
\hline Shared & $.50(.19)$ & $.52(.16)$ & $.30(.18)$ & $.40(.16)$ & $.67(.18)$ \\
\hline Unshared & $.34(.23)$ & $.32(.25)$ & $.34(.28)$ & $.29(.25)$ & $.32(.25)$ \\
\hline
\end{tabular}

Although there was no significant main effect of age group, $F(1,117)=2.53, M S E=.10, p=.11, \eta_{\mathrm{p}}{ }^{2}=.02$, there was a main effect of picture stimulus type, $F(4,468)=42.81, M S E=$ $.03, p<.001, \eta_{\mathrm{p}}{ }^{2}=.27$, as well as an interaction between age group and picture stimulus type, $F(4,468)=4.37, M S E=0.03$, $p=.002, \eta_{\mathrm{p}}{ }^{2}=.04$. As can be seen in Table 3, participants of all ages recalled more of the high arousal negative pictures compared to the other picture types. However, this was particularly true for the younger adults. In other words, across age groups, there was a positivity effect. This did not vary as a function of retrieval condition. There was no interaction between age group, picture stimulus type, and retrieval condition, $F(4$, $468)=1.20, M S E=.03, p=.31, \eta_{\mathrm{p}}{ }^{2}=.01$.

Because the positivity effect is typically defined as an ageby-valence interaction (see Mather, 2016; Reed et al., 2014), we next examined whether or not age group affected recall of positive, neutral, and negative stimuli during this baseline test, regardless of their arousal levels. We also collapsed across information distribution, as this factor is not relevant for the presence or absence of the positivity effect. Indicative of a positivity effect, in a 2 (retrieval condition: collaborative or nominal recall) $\times 2$ (age group: older adults or younger adults) $\times 2$ (picture valence: positive or negative) ANOVA on the proportion of pictures correctly recalled by each group during Recall Test 1, there was a significant interaction between age group and picture valence, $F(1,117)=10.65, M S E=.01, p=$ $.001, \eta_{\mathrm{p}}{ }^{2}=.08$. Follow-up independent-samples $t$ tests showed that younger adults recalled significantly more of the negative pictures (high or low in arousal, shared and unshared), $t(119)=2.39, p=.02, d=.44$, and more of the neutral pictures (shared and unshared), $t(119)=2.37, p=.02, d=.43$, than did the older adults. In contrast to this, this age difference disappeared (and numerically reversed) when examining recall of the positive pictures (high or low in arousal, shared and unshared), $t(119)=1.11, p=.27, d=-.12$ (see Table 3$)$.

\section{The effects of collaboration on recall (Recall Test 2)}

We next turned to our primary study aims: (1) Did the magnitude of collaborative inhibition vary as a function of picture stimulus type? (2) Did the potential effects of picture stimulus type on collaborative inhibition depend upon the participants' age group? and (3) Did the potential effects of information distribution on collaborative inhibition depend upon the picture stimulus type? To address these questions, we ran a 2 (retrieval condition: collaborative or nominal recall) $\times 2$ (age group: older adults or younger adults) $\times 5$ (picture stimulus type: positive high arousal, positive low arousal, neutral, negative low arousal, or negative high arousal) $\times 2$ (information distribution: shared or unshared items) ANOVA on the proportion of pictures correctly recalled by each group during Recall Test 2. Within this analysis there were significant main effects for each of our four factors (i.e., retrieval condition, age group, picture stimulus type, and information distribution). There was also a significant interaction between age group and picture stimulus type, a marginally significant interaction between retrieval condition and information distribution, and a marginally significant interaction between information distribution and picture stimulus type. No other effects were significant (all $p$ s > .14). Below, we further describe these results and their relation to our study hypotheses.

The primary aim of this study was to answer the question: Does the magnitude of collaborative inhibition depend upon the valence and arousal of the to-be-remembered stimuli? Our results suggest that it does not. Although we observed collaborative inhibition (i.e., there was a main effect of retrieval condition), $F(1,117)=9.49, M S E=0.09, p=.003, \eta_{\mathrm{p}}{ }^{2}=$ .08 , this did not depend upon picture stimulus type. As shown in Fig. 1, within this analysis there was no significant interaction between retrieval condition and picture stimulus type, $F(4,468)=0.14, M S E=0.03, p=.97, \eta_{\mathrm{p}}{ }^{2}=.001$.

Did the potential effects of picture stimulus type on collaborative inhibition depend on the participants' age? Although we did not observe an overall effect of picture stimulus type on collaborative inhibition, we had hypothesized that this effect could vary by age. However, results of the aforementioned 2 $($ retrieval condition $) \times 2$ (age group) $\times 5$ (picture stimulus type) $\times 2$ (information distribution) ANOVA did not support this. The magnitude of the collaborative inhibition effect did not vary with age group (i.e., there was no significant interaction between retrieval condition and age group), $F(1,117)=0.14, M S E=$ $.09, p=.71, \eta_{\mathrm{p}}{ }^{2}=.001$. We also did not observe a significant 


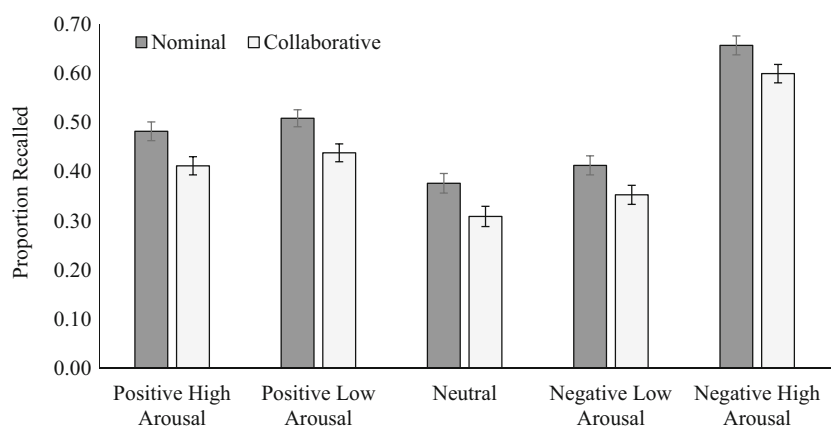

Fig. 1 The proportion of pictures recalled by nominal and collaborative groups (collapsing across age group and information distribution) during Recall Test 2 as a function of picture stimulus type. Error bars represent +/- $S E$ mean

interaction between retrieval condition, age group, and picture stimulus type, $F(4,468)=0.49, M S E=.03, p=.74, \eta_{\mathrm{p}}{ }^{2}=.004$.

Taken together, the previous analyses suggest that collaborative inhibition was invariant to picture stimulus type and age group. To further confirm this, we next conducted a MANOVA, using retrieval condition and age group as the independent variables and total group recall (collapsing across shared and unshared items) in each of the five picture stimulus categories as the dependent variables. Overall, there was a significant multivariate effect of retrieval condition, $F(5,113)=2.55, p=$ $.03, \eta_{\mathrm{p}}{ }^{2}=.10$, as well as a significant multivariate effect of age group, $F(5,113)=6.94, p<.001, \eta_{\mathrm{p}}{ }^{2}=.24$. Collaborative inhibition occurred, and older adults' had poorer memory accuracy than younger adults did. However, there was no significant multivariate interaction between retrieval condition and age group, $F(5,113)=0.79, p=.63, \eta_{\mathrm{p}}{ }^{2}=.03$. As can be seen in Fig. 1, at the univariate level, collaborative inhibition significantly occurred regardless of picture stimulus type (all $p \mathrm{~s}<.032$ ). In no case was this dependent upon age group (all $p \mathrm{~s}>.24$ ). ${ }^{2}$

Although age group did not modulate the magnitude of collaborative inhibition for either neutral or emotional information, this was despite the fact that the positivity effect remained. Within the aforementioned 2 (retrieval condition) $\times 2$ (age group) $\times 5$ (picture stimulus type) $\times 2$ (information distribution) ANOVA, there was a significant interaction between age group and picture stimulus type, $F(1,468)=3.59, M S E=.03, p=$ $.007, \eta_{\mathrm{p}}{ }^{2}=.03$, which did not depend upon retrieval condition, $F(4,468)=0.49, M S E=.03, p=.74, \eta_{\mathrm{p}}^{2}=.004$. Because the positivity effect is defined as an age-by-valence interaction (see Mather, 2016; Reed et al., 2014), in follow-up analyses we again collapsed across arousal levels. As during Recall Test 1 , in a 2 (retrieval condition: collaborative or nominal recall) $\times 2$ (age group: older adults or younger adults) $\times 2$ (picture valence:

\footnotetext{
${ }^{2}$ In a prior study, collaborative groups included fewer categories in their memory output than nominal groups (Hyman, Cardwell, and Roy, 2013). However, in this study there were no group differences in category sampling during the second recall test. With the exception of one older adult collaborative dyad, all other groups remembered at least one item from each of the five valence categories.
}

positive or negative) ANOVA, there was a significant interaction between age group and picture valence, $F(1,117)=8.18$, $M S E=.01, p=.005, \eta_{\mathrm{p}}{ }^{2}=.07$. Follow-up independent $t$ test showed that younger adults continued to recall significantly more of the negative pictures (high or low in arousal, shared and unshared), $t(119)=4.27, p<.001, d=.78$, and more of the neutral pictures (shared and unshared), $t(119)=3.71, p<.001$, $d=.68$, than did the older adults. In contrast, there was no significant age difference when examining recall of the positive pictures (high or low in arousal, shared and unshared), $t(119)=$ $1.33, p=.19, d=.24$.

We next turned to our third, and final, study aim: Did information distribution affect the magnitude of collaborative inhibition, and did this depend on the picture stimulus type? Within the aforementioned 2 (retrieval condition) $\times 2$ (age group) $\times 5$ (picture stimulus type) $\times 2$ (information distribution) ANOVA, there was a main effect of information distribution, $F(1,117)=196.14, M S E=.05, p<.001, \eta_{\mathrm{p}}^{2}=.63$, as well as a marginally significant interaction between information distribution and picture stimulus type, $F(4,468)=2.36$, $M S E=.04, p=.05, \eta_{\mathrm{p}}{ }^{2}=.02$. As during Recall Test 1, groups were more likely to recall the shared compared with the unshared pictures, and this effect was especially true for the emotional pictures compared with the neutral pictures.

Novel to Recall Test 2, and as shown in Fig. 2, there was also a marginally significant interaction between information distribution and retrieval condition, $F(1,117)=3.00, M S E=$ $.05, p=.09, \eta_{\mathrm{p}}{ }^{2}=.03$. This effect did not depend on picture stimulus type, $F(4,468)=0.11, M S E=.04, p=.98, \eta_{\mathrm{p}}{ }^{2}=$ .001 , or age group, $F(1,117)=0.29, M S E=.05, p=.59$, $\eta_{\mathrm{p}}{ }^{2}=.002$. In contrast to the results reported by Meade and Gigone (2011), this interaction arose because collaborative inhibition was robust for the shared stimuli but attenuated for the unshared stimuli. A series of independent $t$ tests, with retrieval condition as the independent variable, confirmed this pattern. When information was shared, collaborative inhibition significantly occurred for each of the five types of stimuli

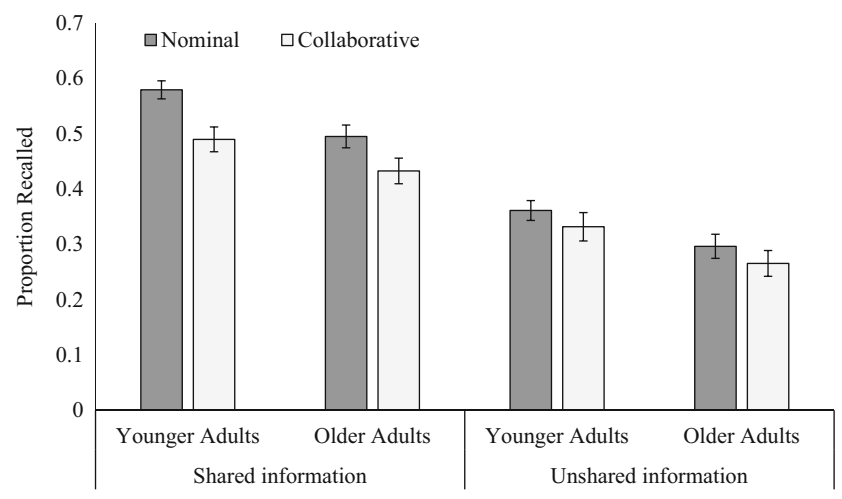

Fig. 2 The proportion of shared and unshared pictures recalled by nominal and collaborative groups (collapsing across picture stimulus type) during Recall Test 2 as a function of age group. Error bars represent $+/-S E$ mean 
(all $p \mathrm{~s}<.04$ ). In contrast, when information was unshared, collaborative inhibition was statistically absent for each of the five types of stimuli (all $p \mathrm{~s}>.21$ ). We return to this pattern of results in the Discussion.

\section{Individual recall performance after collaboration (Recall Test 3)}

The primary outcome of interest in this study was collaborative inhibition; however, we also included a final, always-individual, recall test. We did because collaborative recall is often associated with higher accuracy on subsequent individual memory tests (e.g., Blumen \& Rajaram, 2008, 2009; Blumen \& Stern, 2011; Blumen et al., 2014; Choi et al., 2014; Henkel \& Rajaram, 2011; Rajaram \& Pereira-Pasarin, 2007; Weldon \& Bellinger, 1997; Wissman \& Rawson, 2015). This benefit occurs because collaborative recall can serve as a second study opportunity, reexposing participants to items that they had forgotten but that their group members recalled.

Building on this, we tested how recall accuracy changed from Recall Test 1 to Recall Test 3 as a function of retrieval condition, age group, and picture stimulus type. We also focused only the shared items where reexposure benefits could occur. In a 2 (test: 1 or 3$) \times 2$ (retrieval condition) $\times 2$ (age group) $\times 5$ (picture stimulus type) ANOVA on the proportion of shared pictures recalled by each group, we observed a main effect of test, $F(1,117)=108.34, M S E=.01, p<.001, \eta_{\mathrm{p}}{ }^{2}=$ .48 , which interacted with retrieval condition, $F(1,117)=$ $5.45, M S E=.01, p=.02, \eta_{\mathrm{p}}{ }^{2}=.04$. As in prior studies, recall improvements were greater for the collaborative group participants than for the nominal group participants. There was also an interaction between test and age group, $F(1,117)=21.54$, $M S E=.01, p<.001, \eta_{\mathrm{p}}{ }^{2}=.16$. As in prior research (Henkel, 2007; 2008), improvements across the memory tests were greater for the younger adults than for the older adults. However, there was no significant interaction between test, age group, and retrieval condition, $F(1,117)=0.74, M S E=$ $.01, p=.39, \eta_{\mathrm{p}}{ }^{2}=.01$. Thus, although older adults benefited less from repeated testing, older and younger adults equally benefited from collaborative recall.

Within this analysis, we also observed a main effect of picture stimulus type, $F(4,468)=99.63, M S E=.04, p<.001, \eta_{\mathrm{p}}{ }^{2}$ $=.46$, which interacted with age group, $F(4,468)=2.50, M S E$ $=.04, p=.04, \eta_{\mathrm{p}}{ }^{2}=.02$. This interaction indicated a positivity effect, and the magnitude of this effect did not change from Recall Test 1 to Recall Test 3 (i.e., there was no significant interaction between test, age group, and picture stimulus type), $F(4,468)=0.46, M S E=.01, p=.77, \eta_{\mathrm{p}}{ }^{2}=.004$.

To further confirm the stability of the positivity effect across the recall tests, we conducted a final analysis in which we included all three recall tests and collapsed across arousal levels (since the positivity effect is defined as an age by valence interaction; see Mather, 2016; Reed et al., 2014). In this 3 (test: Recall Test 1,2 , or 3 ) $\times 2$ (valence: negative or positive) $\times 2$ (age group: older adults or younger adults) ANOVA on the proportion of pictures recalled (collapsing across information distribution and arousal), there was a significant Age Group $\times$ Valence interaction, $F(1,119)=7.73$, $M S E=02, p=.01, \eta_{\mathrm{p}}{ }^{2}=.06$; older adults recalled fewer of the negative pictures than the younger adults but the two age groups did not statistically differ in their recall of the positive pictures. However, the magnitude of this positivity effect did not significantly vary across the three tests (i.e., the three-way interaction between test, valence, and age group was not significant), $F(2,238)=1.46, M S E=.002, p=.24, \eta_{\mathrm{p}}{ }^{2}=.01$.

\section{Discussion}

People are more likely to collaboratively reminisce about emotional events compared to neutral events, especially when they are highly arousing. This fact is nicely demonstrated in a series of studies by Luminet, Bouts, Delie, Manstead, and Rimé (2000). Here, participants were asked to watch either a neutral, a mildly negative, or an intensely negative film clip. They then spent 5 minutes in an empty room with a friend while they waited for the next phase of the experiment. Unbeknownst to them, their conversations during this waiting period were surreptitiously audiotaped by the experimenters. Results from three different experiments consistently showed that participants were most likely to spontaneously discuss the intensely negative film clip with their friends as compared to the other two clips.

Given that emotional valence and arousal modulate whether or not events are collaboratively discussed, in the current experiment we examined whether collaborative memory outcomes differ between emotionally evocative and neutral stimuli. In doing so, we focused on whether the magnitude of collaborative inhibition - the robust finding that groups recall less than their predicted potential (Weldon \& Bellinger, 1997) — would vary between positive high arousal, positive low arousal, neutral, negative low arousal, and negative high arousal stimuli. At the outset of this study, we had predicted that people would use emotional valence and arousal as category cues (as evidenced by emotional clustering; Long et al., 2015; Siddiqui \& Unsworth, 2011), and that this clustering would reduce the susceptibility of emotionally evocative information to retrieval strategy disruption and attenuate collaborative inhibition. Although we expected this to be true of all emotionally evocative stimuli, we also predicted that it would be particularly pronounced when the stimuli were negative in valence and high in arousal. However, our results did not support these hypotheses. Although we observed emotional clustering (for all emotional categories except the negative low arousal pictures), collaborative inhibition did not vary in magnitude between the emotional and neutral pictures, and 
this was true regardless of the pictures' valence and arousal levels.

Many explanations can be put forward to explain this null effect. One possibility is that our study was underpowered to observe it. However, this was not the case. As noted earlier, our study had sufficient power to observe even small effect sizes $\left(\eta_{\mathrm{p}}{ }^{2}=0.01\right)$ between retrieval condition and picture stimulus type. Moreover, the interaction that we actually observed between these factors was extremely small $\left(\eta_{\mathrm{p}}{ }^{2}=\right.$ .001 ), suggesting that magnitude differences in collaborative inhibition between emotionally evocative and neutral stimuli are negligible. Rather than an issue of power, the current results instead suggest that variations in categorical structure do not necessarily affect the magnitude of collaborative inhibition that occurs. This conclusion is consistent with some other research findings that also fail to fully support the retrieval strategy disruption explanation of collaborative inhibition. Manipulations of the stimuli's organizational structure sometimes (Barber, Rajaram, \& Fox, 2012; Finlay, Hitch, \& Meudell, 2000; Garcia-Marques, Garrido, Hamilton, \& Ferreira, 2012; Harris, Barnier, \& Sutton, 2013), but do not always (Barber \& Rajaram, 2011; Dahlström, Danielsson, Emilsson, \& Andersson, 2011) lead to changes in collaborative inhibition. Likewise, results of a recent meta-analysis found that the magnitude of collaborative inhibition did not significantly vary between studies that used categorized versus uncategorized lists (Marion \& Thorley, 2016).

In addition to examining the roles of stimuli valence and arousal, in the current study we also tested whether collaborative memory outcomes would vary between younger and older adults. Previous research has shown that collaborative inhibition is age-invariant using neutral stimuli (Blumen \& Stern, 2011; Henkel \& Rajaram, 2011; Meade \& Roediger, 2009; Ross et al., 2008). However, other research has shown age differences in emotional memory outcomes. For example, as people get older, they show a positivity effect, in which they have a relative preference to attend to and remember positive over negative stimuli (see Reed et al., 2014). Because of this, we hypothesized that collaborative memory outcomes may also vary as a function of stimuli valence. However, results also did not support this hypothesis. We observed collaborative inhibition for both younger and older adults. We also observed an age-related positivity effect in emotional memory. However, these effects did not interact; we did not find any evidence of age differences in the magnitude of collaborative inhibition for either emotionally evocative or neutral stimuli.

Age-invariance in collaborative memory outcomes has important implications for the applied value of collaboration among older adults. It has recently been proposed that collaborative recall is a social activity that can be used to maintain or improve older adults' memory (see Blumen, Rajaram, \& Henkel, 2013). Indeed, research has shown that social collaboration on a cognitive task can sometimes attenuate the age differences that are often observed (e.g., Barnier et al., 2014; Derksen et al., 2015). Furthermore, the cost of collaborative inhibition is sometimes absent (e.g., Johansson et al., 2005) or even reversed (Harris et al., 2011) for long-married older couples (for reviews, see Harris et al., 2014; Martin \& Wright, 2008).

Although the majority of research has focused primarily on the negative effects of collaboration on group memory (i.e., collaborative inhibition), there are also positive effects for later individual memory that occur for both younger and older adults (e.g., Blumen \& Rajaram, 2008, 2009; Blumen \& Stern, 2011; Blumen et al., 2014; Choi et al., 2014; Henkel \& Rajaram, 2011; Rajaram \& Pereira-Pasarin, 2007; Weldon \& Bellinger, 1997; Wissman \& Rawson, 2015). Building on this, the current research suggests that the relative cost of collaborative inhibition and the relative down-stream benefits of collaborative recall do not depend upon the participants' age group or the emotional nature of the to-be-remembered information. Thus, these factors should not affect how basic research on collaborative memory is translated into applied settings that can benefit older adults.

The final factor that we examined was the role of information distribution. Prior studies have shown that during group decision making and collaborative recall, people mention shared information more frequently than unshared information (for reviews, see Kerr \& Tindale, 2004; Stasser \& Titus, 2003). However, to perform optimally in a collaborative recall test, it is necessary to complete an exhaustive memory search and recall as much shared and unshared information as possible. Previous research examining the role of information distribution on collaborative inhibition has been inconclusive. In one study with adults, Meade and Gigone (2011) found that collaborative inhibition was marginally greater for unshared than for shared stimuli (Experiment 1), but was similar for unshared and shared information when category labels were provided to the participants (Experiment 2). However, in another study with 9-year-old children, Gummerum et al. (2013) found no significant difference in collaborative inhibition of unshared and shared stimuli, despite the fact that no category labels were provided. In contrast to these findings, we found that collaborative inhibition was numerically greater for the shared stimuli than for the unshared stimuli. This pattern of results diverge from those previously reported but are in line with the retrieval strategy disruption explanation of collaborative inhibition. If an individual hears an item being recalled that she has not studied, this should not disrupt the retrieval plan she has developed for the information that she has studied. Thus, retrieval strategy disruption and collaborative inhibition should be lower for unshared stimuli.

In addition to supporting the retrieval strategy disruption account, our finding of greater collaborative inhibition for shared, rather than unshared, information also complements other research on the part-list cuing effect. The part-list cuing effect is the finding that individuals recall less information 
when provided a partial list of the to-be-remembered information as cues at retrieval as compared to when these cues are not provided (Slamecka, 1968; for a review, see Nickerson, 1984). This effect has also been explained as arising because of retrieval disruption. In this case, it is the cues provided by the experimenter (rather than other items being recalled by a group member) that disrupt the individual participants' organization of the study materials and in turn reduces recall (Basden \& Basden, 1995; Basden, Basden, \& Galloway, 1977). However, prior research has shown that the extent to which these cues are disruptive depends on whether they were studied by the participant; interlist cues (i.e., items studied by the participant) produce greater part-list cuing deficits than extra-list cues (i.e., items not studied by the participant; Andersson, Hitch, \& Meudell, 2006; Roediger, Stellon, \& Tulving, 1977). In a similar fashion, our results show that shared information (which was studied by the participant) produced greater collaborative inhibition than unshared information (which was not studied by the participant).

When considered together, the current study offers mixed support for the retrieval strategy disruption account of collaborative inhibition. Supporting the retrieval strategy disruption account, unshared study information was less susceptible to collaborative inhibition than shared study information. Contradicting the retrieval strategy disruption account, valence and arousal of the study stimuli did not modulate the magnitude of collaborative inhibition, despite the fact that participants clustered the emotional, but not neutral, information together in memory.

These mixed results may be because retrieval strategy disruption is not the only factor underlying collaborative inhibition. For instance, recent research has also implicated retrieval inhibition as an additional underlying factor of collaborative inhibition (Barber, Harris, \& Rajaram, 2015). According to this view, collaboratively recalled information also inhibits the memory representations of nonrecalled information, making them less likely to be subsequently recalled or recognized (e.g., Anderson, Bjork, \& Bjork, 1994; Bäuml \& Aslan, 2004). This may explain why collaborative inhibition did not vary between the emotional and neutral stimuli in the current study. Other research has reported that retrieval inhibition is not always affected by stimuli valence or arousal (e.g., Barber \& Mather, 2012; Barnier, Hung, \& Conway, 2004; Kuhbandner, Bäuml, \& Stiedl, 2009; McNally, Clancy, Barrett, \& Parker, 2004; Wessel \& Merckelbach, 2006; but see Dehli \& Brennen, 2009; Kuhbandner et al., 2009; Moulds \& Kandris, 2006, for evidence of reduced retrieval inhibition for emotional stimuli). Furthermore, research on part-set cuing has also suggested that retrieval disruption is less likely, and retrieval inhibition is more likely, when the study stimuli have a high degree of interitem associations (Bäuml \& Aslan, 2006), as was likely the case for our emotional stimuli.
In addition to these cognitive factors, social factors may also play a role. This may be particularly true for unshared study information. Although collaborative inhibition cannot be explained by social loafing (Weldon, Blair, \& Huebsch, 2000; see also Meade \& Gigone, 2011), it has been suggested that collaborative groups approach the memory task differently than individuals do. Rather than performing an exhaustive memory search that maximizes the number of details recalled, during collaborative recall participants may instead focus more on creating a shared version of the past (see Alea \& Bluck, 2003; Cuc, Koppel, \& Hirst, 2007; Harris, Paterson, \& Kemp, 2008; Hyman, 1994; Hyman et al., 2013). Because of this, unshared information may be filtered out of the group product. In the current study, we minimized group filtering by having an experimenter serve as the scribe during the group recall test. The experimenter recorded all items recalled unless a group member specifically asked them not to write the item down (which was exceedingly rare). This may explain the difference between the results of the current study and the results reported by Meade and Gigone (2011), where a participant served as the scribe. It is possible that when a participant serves as scribe there is greater group filtering of the unshared information and thus greater collaborative inhibition of this information. Future research is needed to test this possibility and also to further explore how the multiple mechanisms underlying collaborative inhibition interact and together lead to collaborative inhibition in recall.

Acknowledgements Thanks are due to Lauran Evans and Rico Velasco for assistance in data collection. The authors declare that the research was conducted in the absence of any commercial or financial relationships that could be construed as a potential conflict of interest.

Author note Sarah J. Barber is now in the Department of Psychology at San Francisco State University.

\section{Compliance with ethical standards}

Funding This work was supported by grants from the National Institute on Aging (Grant Nos. R01-AG025340, R01-AG038043, R01AG046464, and K02-AG032309) and by a Summer Undergraduate Research Fund (SURF) award to Jaime Castrellon from the University of Southern California.

\section{Appendix A}

\section{Calculation of the transition probabilities}

Transition probabilities were calculated using a procedure outlined by Siddiqui and Unsworth (2011). Transition probabilities represent the probability of recalling a certain type of picture given the identity of the proceeding item that was recalled (e.g., the probability of recalling a negative higharousal picture given that that the proceeding picture was a 
negative high-arousal picture versus a neutral picture). Calculations were done separately for each of the five stimulus categories [negative high arousal $(N H)$, negative low arousal $(N L)$, neutral (NEUT), positive low arousal $(P L)$, and positive high arousal $(P H)]$. Intrusions were removed from the recall output prior to computing transitions. For example, consider the output sequence: $N H, N H, N H, N E U T, N L, P L, P L, N E U T$, $N L, N E U T, P H, P H$. In this sequence, the within-category transition probability for negative high arousal pictures is $100 \%$ - all negative high arousal pictures were immediately proceeded by a negative high arousal picture. In contrast, the within-category transition probability for the neutral pictures is $0 \%$-no neutral picture was immediately proceeded by a neutral picture. Because there were five stimulus categories, the probability of $1 / 5$ represents chance. Within-category transition probabilities were only calculated when a participant recalled at least two pictures from the stimulus category. It is not possible to compare transition probabilities across stimulus categories. This is because these ratios are based upon different total numbers of transitions.

\section{References}

Alea, N., \& Bluck, S. (2003). Why are you telling me that? A conceptual model of the social function of autobiographical memory. Memory, $11,165-178$

Anderson, M. C., Bjork, R. A., \& Bjork, E. L. (1994). Remembering can cause forgetting: Retrieval dynamics in long-term memory. Journal of Experimental Psychology: Learning, Memory, and Cognition, 20, 1063-108s7.

Andersson, J., Hitch, G., \& Meudell, P. (2006). Effects of the timing and identity of retrieval cues in individual recall: An attempt to mimic cross-cueing in collaborative recall. Memory, 14, 94-103.

Andersson, J., \& Rönnberg, J. (1995). Recall suffers from collaboration: Joint recall effects of friendship and task complexity. Applied Cognitive Psychology, 9, 199-211.

Andersson, J., \& Rönnberg, J. (1996). Collaboration and memory: Effects of dyadic retrieval on different memory tasks. Applied Cognitive Psychology, 10, 171-181.

Barber, S. J., Harris, C. B., \& Rajaram, S. (2015). Why two heads apart are better than two heads together: Multiple mechanisms underlie the collaborative inhibition effect in memory. Journal of Experimental Psychology: Learning, Memory, and Cognition, 41, 559-566.

Barber, S. J., \& Mather, M. (2012). Forgetting in context: The effects of age, emotion, and social factors on retrieval-induced forgetting. Memory \& Cognition, 40, 874-888.

Barber, S. J., \& Rajaram, S. (2011). Exploring the relationship between retrieval disruption from collaboration and recall. Memory, 19, 462469.

Barber, S. J., Rajaram, S., \& Fox, E. B. (2012). Learning and remembering with others: The key role of retrieval in shaping group recall and collective memory. Social Cognition, 30, 121-132.

Barnier, A., Hung, L., \& Conway, M. (2004). Retrieval-induced forgetting of emotional and unemotional autobiographical memories. Cognition and Emotion, 18, 457-477.

Barnier, A. J., Priddis, A. C., Broekhuijse, J. M., Harris, C. B., Cox, R. E., Addis, D. R., . . \& \& Congleton, A. R. (2014). Reaping what they sow: Benefits of remembering together in intimate couples. Journal of Applied Research in Memory and Cognition, 3, 261-265.

Bärthel, G., Wessel, I., Huntjens, R. J. C., \& Verwoerd, J. (2017). Collaboration enhances later individual memory for emotional material. Memory. doi:10.1080/09658211.2016.1208248.

Basden, D. R., \& Basden, B. H. (1995). Some tests of the retrieval strategy disruption interpretation of part-list cuing inhibition. Journal of Experimental Psychology: Learning, Memory, and Cognition, 21, $1656-1669$.

Basden, B. H., Basden, D. R., Bryner, S., \& Thomas, R. L., III. (1997). A comparison of group and individual remembering: Does collaboration disrupt retrieval strategies? Journal of Experimental Psychology: Learning, Memory, and Cognition, 23, 1176-1189.

Basden, D. R., Basden, B. H., \& Galloway, B. C. (1977). Inhibition with part-list cuing: Some tests of the item strength hypothesis. Journal of Experimental Psychology: Human Learning and Memory, 3, 100108.

Bäuml, K. H., \& Aslan, A. (2004). Part-list cuing as instructed retrieval inhibition. Memory \& Cognition, 32, 610-617.

Bäuml, K. H., \& Aslan, A. (2006). Part-list cuing can be transitory and lasting: The role of encoding. Journal of Experimental Psychology: Learning, Memory, and Cognition, 32, 33-43.

Blumen, H. M., \& Rajaram, S. (2008). Influence of re-exposure and retrieval disruption during group collaboration on later individual recall. Memory, 16, 231-244.

Blumen, H. M., \& Rajaram, S. (2009). Effects of repeated collaborative retrieval on individual memory vary as a function of recall versus recognition tasks. Memory, 17, 840-846.

Blumen, H. M., Rajaram, S., \& Henkel, L. (2013). The applied value of collaborative memory research in aging: Behavioral and neural considerations. Journal of Applied Research in Memory and Cognition, 2, 107-117.

Blumen, H. M., \& Stern, Y. (2011). Short-term and long-term collaboration benefits on individual recall in younger and older adults. Memory \& Cognition, 39, 147-154.

Blumen, H. M., Young, K. E., \& Rajaram, S. (2014). Optimizing group collaboration to improve later retention. Journal of Applied Research in Memory and Cognition, 3, 244-251.

Bradley, M. M., Greenwald, M. K., Petry, M. C., \& Lang, P. J. (1992). Remembering pictures: Pleasure and arousal in memory. Journal of Experimental Psychology: Learning, Memory, and Cognition, 18, 379-390.

Buchanan, T. W., Etzel, J. A., Adolphs, R., \& Tranel, D. (2006). The influence of autonomic arousal and semantic relatedness on memory for emotional words. International Journal of Psychophysiology, $61,26-33$

Carstensen, L. L., Pasupathi, M., Mayr, U., \& Nesselroade, J. R. (2000). Emotional experience in everyday life across the adult life span. Journal of Personality and Social Psychology, 79, 644-655.

Charles, S. T., Mather, M., \& Carstensen, L. L. (2003). Aging and emotional memory: The forgettable nature of negative images for older adults. Journal of Experimental Psychology: General, 132, 310 324.

Chasteen, A. L., Bhattacharyya, S., Horhota, M., Tam, R., \& Hasher, L. (2005). How feelings of stereotype threat influence older adults' memory performance. Experimental Aging Research, 31, 235-260.

Choi, H. Y., Blumen, H. M., Congleton, A. R., \& Rajaram, S. (2014). The role of group configuration in the social transmission of memory: Evidence from identical and reconfigured groups. Journal of Cognitive Psychology, 26, 65-80.

Choi, H. Y., Kensinger, E. A., \& Rajaram, S. (2013). Emotional content enhances true but not false memory for categorized stimuli. Memory \& Cognition, 41, 403-415.

Cohen, J. (1988). Statistical power analysis for the behavioral sciences (2nd ed.). Hillside, NJ: Erlbaum. 
Congleton, A. R., \& Rajaram, S. (2011). The influence of learning methods on collaboration: Prior repeated retrieval enhances retrieval organization, abolishes collaborative inhibition, and promotes postcollaborative memory. Journal of Experimental Psychology: General, 140, 535-551.

Cuc, A., Koppel, J., \& Hirst, W. (2007). Silence is not golden: A case for socially-shared retrieval-induced forgetting. Psychological Science, 18, 727-733.

Dahlström, Ö., Danielsson, H., Emilsson, M., \& Andersson, J. (2011). Does retrieval strategy disruption cause general and specific collaborative inhibition? Memory, 19, 140-154.

Dehli, L., \& Brennen, T. (2009). Does retrieval-induced forgetting occur for emotional stimuli? Cognition and Emotion, 23, 1056-1068.

Derksen, B. J., Duff, M. C., Weldon, K., Zhang, J., Zamba, K. D., Tranel, D., \& Denburg, N. L. (2015). Older adults catch up to younger adults on a learning and memory task that involves collaborative social interaction. Memory, 23, 612-624.

Ekeocha, J. O., \& Brennan, S. E. (2008). Collaborative recall in face-toface and electronic groups. Memory, 16, 245-261.

Faul, F., Erdfelder, E., Lang, A. G., \& Buchner, A. (2007). G*Power 3: A flexible statistical power analysis program for the social, behavioral, and biomedical sciences. Behavior Research Methods, 39, 175-191.

Finlay, F., Hitch, G. J., \& Meudell, P. R. (2000). Mutual inhibition in collaborative recall: Evidence for a retrieval-based account. Journal of Experimental Psychology: Learning, Memory, and Cognition, 26, 1556-1567.

Garcia-Marques, L., Garrido, M. V., Hamilton, D. L., \& Ferreira, M. B. (2012). Effects of correspondence between encoding and retrieval organization in social memory. Journal of Experimental Social Psychology, 48, 200-206.

Gross, J. J., \& John, O. P. (2003). Individual differences in two emotion regulation processes: Implications for affect, relationships, and wellbeing. Journal of Personality and Social Psychology, 85, 348-362.

Gummerum, M., Leman, P. J., \& Hollins, T. S. (2013). Children's collaborative recall of shared and unshared information. British Journal of Developmental Psychology, 31, 302-317.

Harris, C. B., Barnier, A. J., Sutton, J., \& Keil, P. G. (2014). Couples as socially distributed cognitive systems: Remembering in everyday social and material contexts. Memory Studies, 7, 285-297.

Harris, C. B., Barnier, A. J., \& Sutton, J. (2013). Shared encoding and the costs and benefits of collaborative recall. Journal of Experimental Psychology: Learning, Memory, and Cognition, 39, 183-195.

Harris, C. B., Keil, P. G., Sutton, J., Barnier, A. J., \& McIlwain, D. J. (2011). We remember, we forget: Collaborative remembering in older couples. Discourse Processes, 48, 267-303.

Harris, C. B., Paterson, H. M., \& Kemp, R. I. (2008). Collaborative recall and collective memory: What happens when we remember together? Memory, 16, 213-230.

Henkel, L. A. (2007). The benefits and costs of repeated memory tests for young and older adults. Psychology and Aging, 22, 580-595.

Henkel, L. A. (2008). Maximizing the benefits and minimizing the costs of repeated memory tests for older adults. Psychology and Aging, 23, 250-262.

Henkel, L. A., \& Rajaram, S. (2011). Collaborative remembering in older adults: Age-invariant outcomes in the context of episodic recall deficits. Psychology and Aging, 26, 532-545.

Hyman, I. E. (1994). Conversational remembering: Story recall with a peer versus for an experimenter. Applied Cognitive Psychology, 8 , 49-66.

Hyman, I. E., Cardwell, B. A., \& Roy, R. A. (2013). Multiple causes of collaborative inhibition in memory for categorised word lists. Memory, 21, 875-890.

Johansson, N., Andersson, J. A. N., \& Rönnberg, J. (2005). Compensating strategies in collaborative remembering in very old couples. Scandinavian Journal of Psychology, 46, 349-359.
Kellough, J. L., \& Knight, B. G. (2012). Positivity effects in older adults' perceptions of facial emotion: The role of future time perspective. The Journals of Gerontology Series B: Psychological Sciences and Social Sciences, 67, 150-158.

Kennedy, Q., Mather, M., \& Carstensen, L. L. (2004). The role of motivation in the age-related positivity effect in autobiographical memory. Psychological Science, 15, 208-214.

Kensinger, E. A. (2007). Negative emotion enhances memory accuracy: Behavioral and neuroimaging evidence. Current Directions in Psychological Science, 16, 213-218.

Kerr, N. L., \& Tindale, R. S. (2004). Group performance and decision making. Annual Review of Psychology, 55, 623-655.

Kuhbandner, C., Bäuml, K. H., \& Stiedl, F. C. (2009). Retrieval-induced forgetting of negative stimuli: The role of emotional intensity. Cognition and Emotion, 23, 817-830.

Labouvie-Vief, G., \& Medler, M. (2002). Affect optimization and affect complexity: Modes and styles of regulation in adulthood. Psychology and Aging, 17, 571-588.

Lang, P. J., Bradley, M. M., \& Cuthbert, B. N. (1999). International affective picture system (IAPS): Instruction manual and affective ratings. Gainesville: University of Florida.

Long, N. M., Danoff, M. S., \& Kahana, M. J. (2015). Recall dynamics reveal the retrieval of emotional context. Psychonomic Bulletin \& Review, 22, 1328-1333.

Luminet, O., IV, Bouts, P., Delie, F., Manstead, A. S., \& Rimé, B. (2000). Social sharing of emotion following exposure to a negatively valenced situation. Cognition \& Emotion, 14, 661-688.

Luong, G., \& Charles, S. T. (2014). Age differences in affective and cardiovascular responses to a negative social interaction: The role of goals, appraisals, and emotion regulation. Developmental Psychology, 50, 1919-1930.

Manning, S. K., \& Julian, L. (1975). Recall of emotional words. The Journal of General Psychology, 92, 237-244.

Marion, S. B., \& Thorley, C. (2016). A meta-analytic review of collaborative inhibition and postcollaborative memory: Testing the predictions of the retrieval strategy disruption hypothesis. Psychological Bulletin, 142, 1141-1164.

Martin, M., \& Wright, M. (2008). Dyadic cognition in old age: Paradigms, findings, and directions. In S. M. Hofer \& D. Alwin (Eds.), Handbook on cognitive aging: Interdisciplinary perspectives (pp. 629-646). Los Angeles, CA: SAGE.

Mather, M. (2007). Emotional arousal and memory binding: An objectbased framework. Perspectives on Psychological Science, 2, 33-52.

Mather, M. (2016). The affective neuroscience of aging. Annual Review of Psychology, 67, 213-238.

Mather, M., \& Carstensen, L. L. (2005). Aging and motivated cognition: The positivity effect in attention and memory. Trends in Cognitive Sciences, 9, 496-502.

Mather, M., \& Knight, M. (2005). Goal-directed memory: The role of cognitive control in older adults' emotional memory. Psychology and Aging, 20, 554-570.

Mather, M., \& Sutherland, M. R. (2011). Arousal-biased competition in perception and memory. Perspectives on Psychological Science, 6, 114-133.

McNally, R., Clancy, S., Barrett, H., \& Parker, H. (2004). Inhibiting retrieval of trauma cues in adults reporting histories of childhood sexual abuse. Cognition and Emotion, 18, 479-493.

Meade, M. L., \& Gigone, D. (2011). The effect of information distribution on collaborative inhibition. Memory, 19, 417-428.

Meade, M. L., \& Roediger, H. L. (2009). Age differences in collaborative memory: The role of retrieval manipulations. Memory \& Cognition, 37, 962-975.

Mikels, J. A., \& Shuster, M. M. (2016). The interpretive lenses of older adults are not rose-colored-just less dark: Aging and the interpretation of ambiguous scenarios. Emotion, 16, 94-100. 
Moulds, M. L., \& Kandris, E. (2006). The effect of practice on recall of negative material in dysphoria. Journal of Affective Disorders, 91, 269-272.

Nickerson, R. S. (1984). Retrieval inhibition from part-set cuing: A persisting enigma in memory research. Memory \& Cognition, 12, $531-552$.

Ochsner, K. N. (2000). Are affective events richly recollected or simply familiar? The experience and process of recognizing feelings past. Journal of Experimental Psychology: General, 129, 242-261.

Osborne, J. W. (2001). Testing stereotype threat: Does anxiety explain race and sex differences in achievement? Contemporary Educational Psychology, 26, 291-310.

Pereira-Pasarin, L. P., \& Rajaram, S. (2011). Study repetition and divided attention: Effects of encoding manipulations on collaborative inhibition in group recall. Memory \& Cognition, 39, 968-976.

Perlmutter, H. V., \& De Montmollin, G. (1952). Group learning of nonsense syllables. The Journal of Abnormal and Social Psychology, 47, 762-769.

Poldrack, R. A., Wagner, A. D., Phelps, E. A., \& Sharot, T. (2008). How (and why) emotion enhances the subjective sense of recollection. Current Directions in Psychological Science, 17, 147-152.

Rajaram, S. (2011). Collaboration both hurts and helps memory: A cognitive perspective. Current Directions in Psychological Science, 20, $76-81$.

Rajaram, S., \& Pereira-Pasarin, L. P. (2007). Collaboration can improve individual recognition memory: Evidence from immediate and delayed tests. Psychonomic Bulletin \& Review, 14, 95-100.

Rajaram, S., \& Pereira-Pasarin, L. P. (2010). Collaborative memory: Cognitive research and theory. Perspectives on Psychological Science, 5, 649-663.

Reed, A. E., Chan, L., \& Mikels, J. A. (2014). Meta-analysis of the agerelated positivity effect: Age differences in preferences for positive over negative information. Psychology and Aging, 29, 1-15.

Roediger, H. L., Stellon, C. C., \& Tulving, E. (1977). Inhibition from part-list cues and rate of recall. Journal of Experimental Psychology: Human Learning and Memory, 3, 174-188.

Ross, M., Spencer, S. J., Blatz, C. W., \& Restorick, E. (2008). Collaboration reduces the frequency of false memories in older and younger adults. Psychology and Aging, 23, 85-92.

Ross, M., Spencer, S. J., Linardatos, L., Lam, K. C., \& Perunovic, M. (2004). Going shopping and identifying landmarks: Does collaboration improve older people's memory? Applied Cognitive Psychology, 18, 683-696.

Sharot, T., Delgado, M. R., \& Phelps, E. A. (2004). How emotion enhances the feeling of remembering. Nature Neuroscience, 7, 1376-1380.

Shuell, T. J. (1969). Clustering and organization in free recall. Psychological Bulletin, 72, 353-374.

Siddiqui, A. P., \& Unsworth, N. (2011). Investigating the role of emotion during the search process in free recall. Memory \& Cognition, 39, $1387-1400$

Slamecka, N. J. (1968). An examination of trace storage in free recall. Journal of Experimental Psychology, 76, 504-513.

Stasser, G., \& Titus, W. (2003). Hidden profiles: A brief history. Psychological Inquiry, 14, 304-313.
Stasser, G., Vaughan, S. I., \& Stewart, D. D. (2000). Pooling unshared information: The benefits of knowing how access to information is distributed among group members. Organisational Behavior and Human Decision Processes, 82, 102-116.

Stewart, D. D., Stewart, C. B., Tyson, C., Vinci, G., \& Fioti, T. (2004). Serial position effects and the picture-superiority effect in the group recall of shared information. Group Dynamics: Theory, Research and Practice, 8, 166-181.

Talmi, D., \& Moscovitch, M. (2004). Can semantic relatedness explain the enhancement of memory for emotional words? Memory \& Cognition, 32, 742-751.

Talmi, D., Schmmack, U., Paterson, T., \& Moscovitch, M. (2007). The role of attention and relatedness in emotionally enhanced memory. Emotion, 7, 89-102.

Tulving, E. (1965). The effect of order presentation on learning of "unrelated words". Psychonomic Science, 3, 337-338.

Tulving, E., \& Pearlstone, Z. (1966). Availability versus accessibility of information in memory for words. Journal of Verbal Learning and Verbal Behavior, 5, 381-391.

Vredeveldt, A., Hildebrandt, A., \& von Koppen, P. J. (2016). Acknowledge, repeat, rephrase, elaborate: Witnesses can help each other remember more. Memory, 24, 669-682.

Wallace, W. P. (1970). Consistency of emission order in free recall. Journal of Verbal Learning and Verbal Behavior, 9, 58-68.

Wegner, D. M. (1987). Transactive memory: A contemporary analysis of the group mind. In Theories of Group Behavior (pp. 185-208). New York, NY: Springer.

Wegner, D. M., Giuliano, T., \& Hertel, P. T. (1985). Cognitive interdependence in close relationships. In W. Ickes (Ed.), Compatible and incompatible relationships (pp. 253-276). New York, NY: Springer.

Weldon, M. S., \& Bellinger, K. D. (1997). Collective memory: Collaborative and individual processes in remembering. Journal of Experimental Psychology: Learning, Memory, and Cognition, 23, $1160-1175$.

Weldon, M. S., Blair, C., \& Huebsch, P. D. (2000). Group remembering: Does social loafing underlie collaborative inhibition? Journal of Experimental Psychology: Learning, Memory, and Cognition, 26, $1568-1577$.

Wessel, I., \& Merckelbach, H. (2006). Forgetting "murder" is not harder than forgetting "circle": Listwise-directed forgetting of emotional words. Cognition \& Emotion, 20, 129-137.

Wessel, I., Zandstra, A. R. E., Hengeveld, H. M., \& Moulds, M. L. (2015). Collaborative recall of details of an emotional film. Memory, 23, 437-444.

Wissman, K. T., \& Rawson, K. A. (2015). Why does collaborative retrieval improve memory? Enhanced relational and item-specific processing. Journal of Memory and Language, 84, 75-87.

Yaron-Antar, A., \& Nachson, I. (2010). Collaborative remembering of emotional events: The case of Rabin's assassination. Memory, 14, 46-56.

Zimmerman, C. A., \& Kelley, C. M. (2010). "I'll remember this!” Effects of emotionality on memory predictions versus memory performance. Journal of Memory and Language, 62, 240-253. 